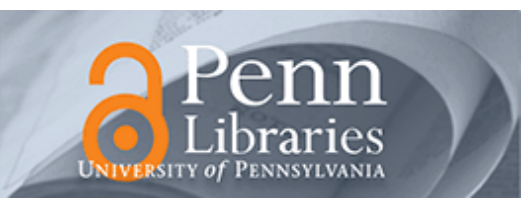

University of Pennsylvania

ScholarlyCommons

6-4-2009

\title{
Diffuse optical monitoring of hemodynamic changes in piglet brain with closed head injury
}

\author{
Chao Zhou \\ University of Pennsylvania
}

Stephanie A. Eucker

University of Pennsylvania, saeucker@mail.med.upenn.edu

Turgut Durduran

University of Pennsylvania, durduran@sas.upenn.edu

Guoqiang Yu

University of Pennsylvania, guoqiang@dept.physics.upenn.edu

Jill Ralston

University of Pennsylvania, ralston@seas.upenn.edu

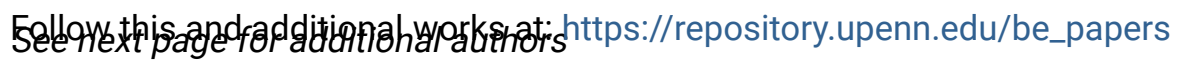

\section{Recommended Citation}

Zhou, C., Eucker, S. A., Durduran, T., Yu, G., Ralston, J., Friess, S. H., Ichord, R. N., Margulies, S. S., \& Yodh, A. G. (2009). Diffuse optical monitoring of hemodynamic changes in piglet brain with closed head injury. Retrieved from https://repository.upenn.edu/be_papers/135

Copyright 2009. Society of Photo-Optical Instrumentation Engineers. One print or electronic copy may be made for personal use only. Systematic reproduction and distribution, duplication of any material in this paper for a fee or for commercial purposes, or modification of the content of the paper are prohibited.

Diffuse optical monitoring of hemodynamic changes in piglet brain with closed head injury Chao Zhou, Stephanie A. Eucker, Turgut Durduran, Guoqiang Yu, Jill Ralston, Stuart H. Friess, Rebecca N. Ichord, Susan S. Margulies, and Arjun G. Yodh, J. Biomed. Opt. 14, 034015 (2009), DOI:10.1117/1.3146814

URL: ttp://dx.doi.org/10.1117/1.3146814

This paper is posted at ScholarlyCommons. https://repository.upenn.edu/be_papers/135

For more information, please contact repository@pobox.upenn.edu. 


\title{
Diffuse optical monitoring of hemodynamic changes in piglet brain with closed head injury
}

\begin{abstract}
We used a nonimpact inertial rotational model of a closed head injury in neonatal piglets to simulate the conditions following traumatic brain injury in infants. Diffuse optical techniques, including diffuse reflectance spectroscopy and diffuse correlation spectroscopy (DCS), were used to measure cerebral blood oxygenation and blood flow continuously and noninvasively before injury and up to $6 \mathrm{~h}$ after the injury. The DCS measurements of relative cerebral blood flow were validated against the fluorescent microsphere method. A strong linear correlation was observed between the two techniques $(R=0.89$, $\mathrm{p}<0.00001)$. Injury-induced cerebral hemodynamic changes were quantified, and significant changes were found in oxy- and deoxy-hemoglobin concentrations, total hemoglobin concentration, blood oxygen saturation, and cerebral blood flow after the injury. The diffuse optical measurements were robust and also correlated well with recordings of vital physiological parameters over the 6-h monitoring period, such as mean arterial blood pressure, arterial oxygen saturation, and heart rate. Finally, the diffuse optical techniques demonstrated sensitivity to dynamic physiological events, such as apnea, cardiac arrest, and hypertonic saline infusion. In total, the investigation corraborates potential of the optical methods for bedside monitoring of pediatric and adult human patients in the neurointensive care unit.
\end{abstract}

\section{Comments}

Copyright 2009. Society of Photo-Optical Instrumentation Engineers. One print or electronic copy may be made for personal use only. Systematic reproduction and distribution, duplication of any material in this paper for a fee or for commercial purposes, or modification of the content of the paper are prohibited.

Diffuse optical monitoring of hemodynamic changes in piglet brain with closed head injury Chao Zhou, Stephanie A. Eucker, Turgut Durduran, Guoqiang Yu, Jill Ralston, Stuart H. Friess, Rebecca N. Ichord, Susan S. Margulies, and Arjun G. Yodh, J. Biomed. Opt. 14, 034015 (2009), DOI:10.1117/1.3146814

URL: ttp://dx.doi.org/10.1117/1.3146814

\section{Author(s)}

Chao Zhou, Stephanie A. Eucker, Turgut Durduran, Guoqiang Yu, Jill Ralston, Stuart H. Friess, Rebecca N. Ichord, Susan S. Margulies, and Arjun G. Yodh 


\section{Diffuse optical monitoring of hemodynamic changes in piglet brain with closed head injury}

\author{
Chao Zhou \\ University of Pennsylvania \\ Department of Physics and Astronomy \\ 209 South 33rd Street \\ Philadelphia, Pennsylvania 19104
}

\author{
Stephanie A. Eucker \\ University of Pennsylvania \\ Department of Bioengineering \\ 3451 Walnut Street \\ Philadelphia, Pennsylvania 19104
}

\author{
Turgut Durduran \\ University of Pennsylvania \\ Department of Physics and Astronomy \\ and \\ Department of Radiology \\ 209 South 33rd Street \\ Philadelphia, Pennsylvania 19104 \\ and \\ ICFO-Institut de Ciencies Fotoniques \\ Mediterranean Technology Park \\ Castelldefels (Barcelona) \\ Spain 08860
}

\section{Guoqiang Yu}

University of Pennsylvania

Department of Physics and Astronomy

209 South 33rd Street

Philadelphia, Pennsylvania 19104

and

University of Kentucky

Center for Biomedical Engineering

Wenner-Gren Research Laboratory

Lexington, Kentucky 40506

\section{Jill Ralston}

\section{Stuart H. Friess}

University of Pennsylvania

Department of Bioengineering

3451 Walnut Street

Philadelphia, Pennsylvania 19104

\section{Rebecca N. Ichord}

University of Pennsylvania School of Medicine

Division of Neurology

Children's Hospital of Philadelphia

Philadelphia, Pennsylvania 19104

Address all correspondence to: Arjun G. Yodh, Department of Physics \& Astronomy, University of Pennsylvania, Philadelphia, PA, 19104. E-mail: yodh@physics.upenn.edu.

\author{
Susan S. Margulies \\ University of Pennsylvania \\ Department of Bioengineering \\ 3451 Walnut Street \\ Philadelphia, Pennsylvania 19104
}

\author{
Arjun G. Yodh \\ University of Pennsylvania \\ Department of Physics and Astronomy \\ 209 South 33rd Street \\ Philadelphia, Pennsylvania 09104 \\ E-mail: yodh@physics.upenn.edu
}

Abstract. We used a nonimpact inertial rotational model of a closed head injury in neonatal piglets to simulate the conditions following traumatic brain injury in infants. Diffuse optical techniques, including diffuse reflectance spectroscopy and diffuse correlation spectroscopy (DCS), were used to measure cerebral blood oxygenation and blood flow continuously and noninvasively before injury and up to $6 \mathrm{~h}$ after the injury. The DCS measurements of relative cerebral blood flow were validated against the fluorescent microsphere method. A strong linear correlation was observed between the two techniques $(R=0.89$, $p<0.00001)$. Injury-induced cerebral hemodynamic changes were quantified, and significant changes were found in oxy- and deoxy-hemoglobin concentrations, total hemoglobin concentration, blood oxygen saturation, and cerebral blood flow after the injury. The diffuse optical measurements were robust and also correlated well with recordings of vital physiological parameters over the 6-h monitoring period, such as mean arterial blood pressure, arterial oxygen saturation, and heart rate. Finally, the diffuse optical techniques demonstrated sensitivity to dynamic physiological events, such as apnea, cardiac arrest, and hypertonic saline infusion. In total, the investigation corraborates potential of the optical methods for bedside monitoring of pediatric and adult human patients in the neurointensive care unit. $\odot 2009$ Society of Photo-Optical Instrumentation Engineers. [DOI: 10.1117/1.3146814]

Keywords: diffuse correlation spectroscopy (DCS); diffuse reflectance spectroscopy (DRS); cerebral hemodynamics; cerebral blood flow; traumatic brain injury; near-infrared spectroscopy (NIRS).

Paper 09057 received Feb. 18, 2009; accepted for publication Mar. 25, 2009; published online Jun. 4, 2009.

\section{Introduction}

Traumatic brain injury (TBI) is a leading cause of childhood morbidity and mortality in the United States, with an annual rate of $\sim 200$ per 100,000 children requiring hospitalization. ${ }^{1}$ The increasing monetary costs result not only from the acute intensive care for these patients but also from long-term care

1083-3668/2009/14(3)/034015/11/\$25.00 @ 2009 SPIE 
that is often necessary. Brain injuries in these patients result from both the primary trauma and secondary insults, such as reductions in cerebral blood flow, derangements in cerebral metabolism, and the ensuing ischemic injuries that continue to progress well after the traumatic event. Optimal therapeutic efficacy thus requires knowledge of cerebral blood flow, oxygen supply, and oxygen consumption in patients after TBI. In this study, we explored the feasibility of two diffuse optical techniques, diffuse reflectance spectroscopy (DRS) and diffuse correlation spectroscopy (DCS), for continuous, noninvasive measurement of cerebral blood flow and blood oxygenation at the bedside.

The study employed a nonimpact inertial rotational model of a closed head injury in neonatal piglets, which produces a diffuse pattern of axonal injury similar to that observed in severely head-injured infants. ${ }^{2}$ The piglet brain is a good model because the gyral pattern, distribution of gray and white matter, and normal cerebral blood flow and metabolism are similar to those of human infants. ${ }^{3}$ The pathology resulting from this rotational head injury has been well characterized and includes axonal injury in both central and peripheral white matter, as well as subdural and subarachnoid blood over the cerebral hemispheres, particularly at the frontal lobes. ${ }^{2}$ Furthermore, neurobehavioral deficits in visual-based problem solving and exploration have been observed. ${ }^{4}$ However, the effects of this injury model on cerebral blood flow (CBF) have not yet been investigated.

Recently, near-infrared (NIR) diffuse optical techniques have been employed in research and clinical settings to noninvasively characterize cerebral hemodynamics, including oxy- and deoxy-hemoglobin concentrations $\left(\mathrm{HbO}_{2}\right.$ and $\left.\mathrm{Hb}\right)$, blood oxygen saturation $\left(\mathrm{StO}_{2}\right)$, total hemoglobin concentration (THC), ${ }^{5,6}$ and to a lesser extent, blood flow. ${ }^{7-11}$ Many existing CBF measurement technolodgies have obvious limitations. For example, bolus injections of indocyanine green, ${ }^{12}$ or radioactive ${ }^{13}$ and fluorescent microspheres, ${ }^{14,15}$ only measure CBF at a few discrete time points. Transcranial Doppler ultrasonography ${ }^{16}$ measures flow velocities in only large vessels including the major cerebral arteries. Laser Doppler flowmetry ${ }^{17}$ requires opening of the scalp and skull for probe placement on the dura directly due to its shallow penetration. In contrast, NIR diffuse optical techniques permit continuous noninvasive measurements of cerebral hemodynamics in microvasculatures. DRS, also known as NIR spectroscopy, was introduced $^{18}$ in 1977 and has been successfully used to measure hemoglobin concentration and blood oxygen saturation in both human infants ${ }^{19-21}$ and newborn piglets, whose scalps and skulls are thin enough to ensure a high signal-to-noise ratio. $^{22-25}$ However, continuous noninvasive CBF measurements in human infants and piglets have been limited until now.

In this contribution, $\mathrm{DCS},{ }^{26,27}$ also known as diffusingwave spectroscopy ${ }^{28,29}$ is employed for the continuous measurement of CBF through the intact scalp and skull in a newborn piglet TBI model. Relative cerebral blood flow (rCBF) measured with DCS and normalized by preinjury CBF was found to correlate strongly with $\mathrm{rCBF}$ measured using the fluorescent microsphere (FM) technique. In addition, DRS was used to simultaneously assess cerebral $\mathrm{HbO}_{2}, \mathrm{Hb}$, THC, and $\mathrm{StO}_{2}$ noninvasively. TBI was found to have a significant impact on all of these cerebral hemodynamic parameters. Diffuse optical techniques were robust for the entire $6 \mathrm{~h}$ measured after injury and were sensitive to spontaneous, transient physiological events, such as apnea, cardiac arrest, and hypertonic saline infusion. The optically measured cerebral hemodynamics after injury were consistent with vital physiological recordings, including mean arterial blood pressure (MAP), arterial oxygen saturation $\left(\mathrm{SaO}_{2}\right)$, and heart rate (HR). The potential of diffuse optical techniques for bedside monitoring of cerebral hemodynamics in the neurointensive care unit is thus demonstrated.

\section{Materials and Methods}

\subsection{Animal Preparation and Measurement Procedure}

Animal procedures were conducted in accordance with the guidelines established by the National Institutes of Health and were approved by the Institutional Animal Care and Use Committee at the University of Pennsylvania. Eighteen anesthetized three- to five-day-old female piglets were used for the study. Each animal in group $1(n=10)$ received a single rotational injury, each animal in group $2(n=4)$ received a sham injury, and each animal in group $3(n=4)$ received a single rotational injury and a 5-min hypertonic saline infusion at 30 min postinjury (see Table 1). Each animal was intubated and maintained on 2.0-2.5\% isoflurane. Catheters were placed in the femoral arteries for blood pressure monitoring and reference microsphere blood withdrawals, in the femoral vein for saline and phenylephrine infusion, and in the left ventricle of the heart via the right carotid artery for fluorescent microsphere injections. Vital physiological parameters, including MAP (in $\mathrm{mmHg}$ ), HR in beats per minute (BPM), arterial oxygen saturation $\left[\mathrm{SaO}_{2}\right.$ (in percent)], end-tidal $\mathrm{CO}_{2}\left[\mathrm{EtCO}_{2}\right.$ (in $\mathrm{mmHg}$ )], and body temperature [ $T$ (in degrees Celsius) were manually recorded every $5 \mathrm{~min}$ for the duration of each study; continuous recordings were conducted whenever available. Supplemental oxygen and mechanical ventilator support were used as needed to maintain normoxia and normocarpnia.

The piglet scalp was shaved for the optical measurements, and baseline optical readings were obtained. The optical probe was then removed, and the piglet head was secured to a padded snout clamp mounted to the linkage assembly of a HYGE pneumatic actuator (Bendix Corp., Southfield, Michigan), which converts an impulsive linear motion to a rotational motion. ${ }^{2}$ Immediately prior to injury, anesthesia was withdrawn. Brain injury was induced by a single rapid, nonimpact $90 \mathrm{deg}$ rotation of the head in the horizontal plane, with a mean peak-angular velocity of $204 \mathrm{rad} / \mathrm{s}$ in group 1 and $209 \mathrm{rad} / \mathrm{s}$ in group 3. The center of rotation was the midcervical spine. After injury, the animal was taken off the snout clamp, and the optical probe was repositioned on the scalp. Reflexive withdrawal to a pinch stimulus was assessed every minute for the first $15 \mathrm{~min}$, then every $3 \mathrm{~min}$ thereafter. When the pinch reflex was positive, indicating return of consciousness, anesthesia was resumed. Phenylephrine was administered as needed to maintain MAP above $40 \mathrm{mmHg}$ and within $10 \mathrm{mmHg}$ of preinjury baseline levels. Changes in cerebral blood oxygenation, hemoglobin concentration, and blood flow relative to baseline were continuously measured with the optical probe beginning within the first $2-5 \mathrm{~min}$ after injury and 
Table 1 Summary of all animals used in the study. $\mathrm{CA}^{+}$: cardiac arrest; $\mathrm{HS}^{*}$ : hypertonic (3\%) saline.

\begin{tabular}{|c|c|c|c|c|c|c|c|c|}
\hline \multirow[b]{2}{*}{ ID } & \multirow[b]{2}{*}{ Group } & \multicolumn{4}{|c|}{ Continuous monitoring } & \multicolumn{3}{|c|}{ Dynamic physiological events } \\
\hline & & $\mathrm{DRS}+\mathrm{DCS}$ & MAP & $\mathrm{SaO}_{2}$ & $\mathrm{HR}$ & Apnea & Apnea $+\mathrm{CA}^{+}$ & HS* infusion \\
\hline 1 & 1 & yes & no & no & no & 2 & 0 & 0 \\
\hline 2 & 1 & yes & no & no & no & 1 & 0 & 0 \\
\hline 3 & 1 & yes & no & no & no & 0 & 0 & 0 \\
\hline 4 & 1 & yes & no & no & no & 1 & 0 & 0 \\
\hline 5 & 1 & yes & no & no & no & 1 & 0 & 0 \\
\hline 6 & 1 & yes & yes & yes & yes & 0 & 0 & 0 \\
\hline 7 & 1 & yes & yes & yes & yes & 0 & 0 & 0 \\
\hline 8 & 1 & yes & yes & yes & yes & 0 & 0 & 0 \\
\hline 9 & 1 & yes & yes & yes & yes & 1 & 0 & 0 \\
\hline 10 & 1 & yes & yes & yes & yes & 0 & 0 & 0 \\
\hline 11 & 2 & yes & yes & no & no & 0 & 0 & 0 \\
\hline 12 & 2 & yes & yes & yes & yes & 2 & 0 & 0 \\
\hline 13 & 2 & yes & yes & yes & yes & 0 & 0 & 0 \\
\hline 14 & 2 & yes & yes & yes & yes & 0 & 0 & 0 \\
\hline 15 & 3 & yes & yes & no & no & 1 & 2 & 1 \\
\hline 16 & 3 & yes & yes & no & no & 1 & 0 & 1 \\
\hline 17 & 3 & yes & yes & no & no & 0 & 0 & 1 \\
\hline 18 & 3 & yes & yes & yes & yes & 0 & 0 & 1 \\
\hline
\end{tabular}

until $6 \mathrm{~h}$ postinjury. Spontaneous physiological events, such as apnea (a period when an animal suspends breathing ${ }^{30}$ ) and cardiac arrest, and physiological perturbations, such as hypertonic saline infusion, were noted during the monitoring period and were used to investigate possible hemodynamic signatures in corresponding optical recordings. At $6 \mathrm{~h}$ postinjury, each piglet was sacrificed by an overdose of pentabarbital and the brain was perfusion fixed in formalin for fluorescent microsphere analysis.

\subsection{DRS}

DRS was employed to measure cerebral blood oxygenation and hemoglobin concentrations of tissues located several centimeters into the brain through intact scalp and skull. A semiinfinite differential path-length factor method based on a modified Beer-Lambert law ${ }^{23,31}$ was employed to analyze the changes in light absorption $\left(\mu_{\mathrm{a}}\right)$ at each wavelength $(685$, 785 , and $830 \mathrm{~nm})$. Changes in oxy-hemoglobin concentration $\left(\Delta \mathrm{HbO}_{2}\right)$ and deoxy-hemoglobin concentration $(\Delta \mathrm{Hb})$ were extracted from the wavelength-dependent $\Delta \mu_{\mathrm{a}}$. The combination of these data yielded changes in total hemoglobin concentration $\left(\mathrm{THC}=\Delta \mathrm{HbO}_{2}+\Delta \mathrm{Hb}+\mathrm{THC}_{0}\right)$ and blood oxygen saturation $\left(\mathrm{StO}_{2}=\left[\left(\Delta \mathrm{HbO}_{2}+\mathrm{THC}_{0} \cdot \mathrm{StO}_{20}\right) / \mathrm{THC}\right] \times 100 \%\right)$, wherein the baseline $\mathrm{THC}\left(\mathrm{THC}_{0}\right)$ and blood oxygenation $\left(\mathrm{StO}_{20}\right)$ in the healthy piglet brain were assumed to be $42 \mu \mathrm{M}$ and $60 \%$, respectively. ${ }^{23,32}$ The reduced light scattering coefficient $\left(\mu_{\mathrm{s}}^{\prime}\right)$ of the piglet brain was assumed to be $10 \mathrm{~cm}^{-1},{ }^{24,32}$ for analysis of the hemoglobin concentrations. Note, a prefix " $r$ " is used throughout the paper to indicate the relative change of a parameter compared to its baseline level (e.g., $\mathrm{rTHC}=\mathrm{THC} / \mathrm{THC}_{0}$ ).

\subsection{DCS}

Diffuse light also carries dynamic information about moving scatterers below the tissue surface [i.e., red blood cells (RBCs)]. In this case, a continuous wave, long-coherencelength laser is used as the light source $(785 \mathrm{~nm})$. The speckle intensity temporal fluctuations, due to movements of the scatterers, is detected using a single-mode (or few-mode) optical fiber coupled to a high-sensitivity photon-counting detector. The decay rate of the temporal autocorrelation function of the detected intensity reveals tissue blood flow information (e.g., faster decay indicates higher blood flow. ${ }^{7-11,26,33-35}$ A correlation diffusion equation ${ }^{27}$ is used to model the propagation of 


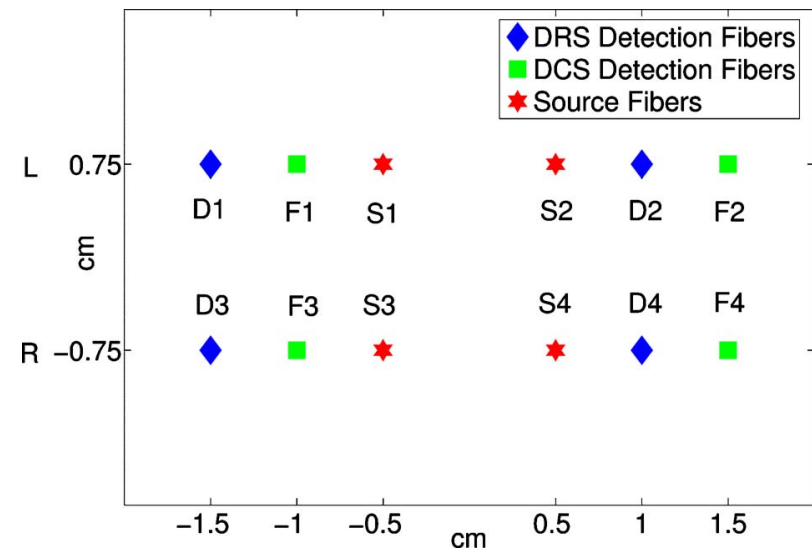

Fig. 1 Arrangement of the optical probe. Four multimode source fibers $(\star)$, four 1 -mm DRS fibers $(\star)$, and four single-mode DCS fibers (ם) were used for simultaneous DRS and DCS measurements. The fibers were arranged into two columns, oriented anteriorly posteriorly along most of the length of the left and right cerebral hemispheres on top of the piglet head. The source-detector separations ranged from $5 \mathrm{~mm}$ to $2 \mathrm{~cm}$.

the autocorrelation function in turbid media. The decay rate of the intensity autocorrelation function depends on tissue optical properties $\left(\mu_{a}\right.$ and $\left.\mu_{\mathrm{s}}^{\prime}\right)$, and a flow-index $\left(\alpha D_{\mathrm{b}}\right)$, where $\alpha$ is a unitless factor representing the fraction of scatterers that are moving (e.g., RBCs) and $D_{\mathrm{b}}$ is an effective Brownian motion coefficient of the scatterers. We have observed in tissue studies that changes in $\alpha D_{b}$ correlate well with other flow measurement modalities such as laser Doppler, ${ }^{7,36}$ colorweighted power Doppler ultrasound, ${ }^{33}$ Xenon $\mathrm{CT},{ }^{37}$ and arterial-spin-labeling magnetic resonance imaging (ASL-MRI) ${ }^{38,39}$ Therefore, we report $\mathrm{rCBF}=\alpha D_{\mathrm{b}} /\left(\alpha D_{\mathrm{b}}\right)_{0}$ to indicate the $\mathrm{CBF}$ values in the piglet brain relative to the baseline (preinjury) measurements. The absorption coefficient $\left(\mu_{\mathrm{a}}\right)$ of the piglet brain at $785 \mathrm{~nm}$ was obtained from the DRS analysis and was used in a semi-infinite $\operatorname{model}^{26}$ to fit to the DCS auto-correlation curves and thus to minimize the influence of THC changes on $\mathrm{rCBF}$ measurements. Noise in the DCS correlation curve was estimated based on the model described previously and was employed herein to improve curve fitting. ${ }^{9}$

\subsection{Hybrid Instrumentation and Optical Probe}

A hybrid instrument combining both the DRS and DCS techniques was used for piglet measurements. ${ }^{40,41}$ Three intensity modulated $(70 \mathrm{MHz})$ diode lasers $(685,785$, and $830 \mathrm{~nm})$ and a 785-nm-long coherence-length laser (Crystalaser, reno, Nevada) were coupled to a $4 \times 1$ optical switch (Dicon, Richmond, California), which enabled time sharing of the DRS and DCS measurements. The output of the source wavelength switch was fed into a second $1 \times 4$ optical switch, which scanned over the four source positions on the optical probe (see Fig. 1). Four 1-mm optical fibers were used for DRS detection, and four single-mode optical fibers were used for DCS detection. The fibers were arranged into two columns, probing the left and right hemispheres of the piglet brain, respectively. The source-detector separation ranged from $5 \mathrm{~mm}$ to $2 \mathrm{~cm}$, and the measurement at each position took $\sim 4 \mathrm{~s}$, corresponding to a data acquisition rate of $\sim 4$ frames/min with each frame covering all four source positions. This rate is sufficient for capturing dynamic physiological changes on the scale of several minutes (see Section 3.5). Whenever available (see Table 1), analog outputs from a blood pressure monitor (Grass Technologies, West Warwick, Rhode Island) and a pulse oxymeter (Nellcor Puritan Bennett Inc., Boulder, Colorado) were continuously recorded concurrent with the DRS and DCS measurements. The system was fully automated, and marks were made and saved for the coregistration of various events.

A custom opaque black hood was used to secure the optical probe onto the piglet head. A marker pen was used to outline the probe position so that the probe was placed at the same location on the piglet scalp before and after injury. In order to assess the influence of probe placement repeatability on the accuracy of the diffuse optical measurements, the optical probe was removed from the piglet head after the first baseline measurement and replaced about 1 min later for a second baseline measurement. These double-baseline measurements were conducted before injury in six animals.

\subsection{Fluorescent Microsphere Measurements of Cerebral Blood Flow}

In this study, $\mathrm{FMs}^{14,15}$ were used to measure $\mathrm{CBF}$ for comparison to the optical method. Prior to injury, catheters were surgically placed in the femoral artery for FM reference blood withdrawals, and catheters were surgically plugged in the left ventricle of the heart via the right carotid artery for FM injections. At each time point, $1-2 \times 10^{6} 15$ - $\mu \mathrm{m}$-diam fluorescently labeled microspheres (Molecular Probes, Invitrogen, Carlsbad, California) were injected into the left ventricle with $10 \mathrm{~mL}$ of heparinized saline for $30 \mathrm{~s}$. A reference blood sample was withdrawn at $0.97 \mathrm{~mL} / \mathrm{min}$ from the femoral artery beginning 5-10 s before injection and continuing until $90 \mathrm{~s}$ after injection completion. Fluorescent microspheres having different excitation/emission spectra were injected during baseline optical measurements and at discrete time points postinjury (30 $\mathrm{min}, 1 \mathrm{~h}$, and $6 \mathrm{~h}$ ).

Fixed brains were cut into 3 -mm-thick coronal sections. Sections were embedded in $2 \%$ agarose gel and cut by vibratome (Leica VT1000S, Leica Microsystems GmbH, Wetzlar, Germany) into 100-200- $\mu$ m-thick slices, which were then mounted onto microscope slides with gel mount (Biomeda, Foster City, California). Reference blood samples were filtered four times using $10-\mu \mathrm{m}$-pore polycarbonate membranes (Osmonics, Minnetonka, Minnesota) to retrieve reference FMs, and filters were mounted on large microscope slides. All slides were imaged on a fluorescent slide reader (Alpha Innotech, San Leandro, California) using multiple excitation-emission wavelength pairs to isolate each FM color. FMs of each color were counted in tissue sections and filters using an automated particle counting program to determine $\mathrm{CBF}$ in the upper cerebrum to a tissue depth of $\sim 1.8 \mathrm{~cm}$, corresponding to the top of the lateral ventricles, at different time points before and after injury. $\mathrm{CBF}$ relative to preinjury (rCBF) was calculated from $\mathrm{rCBF}=(m s$ $\left.\times r s_{0}\right) /\left(m s_{0} \times r s\right)$, where $m s$ is the number of tissue microspheres, $r s$ is the number of reference blood microspheres, $m s_{0}$ is the number of tissue microspheres at preinjury base- 


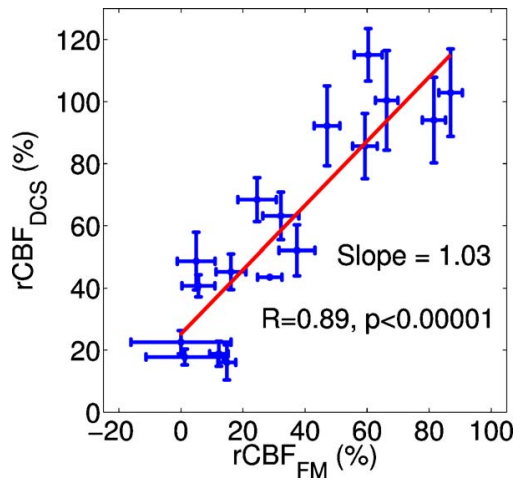

Fig. 2 Correlation between rCBF measured by DCS and fluorescent microspheres. A linear relationship between the two techniques $(R=0.89, p<0.00001)$ was observed. The slope (1.03) is not significantly different from that of identity $(p=0.80)$. The intercept is $25.2 \%$, with a $95 \%$ confidence interval from 12.4 to $38.0 \%$.

line, and $r s_{0}$ is the number of reference blood microspheres at preinjury baseline. The FM measurements were then compared to rCBF as determined optically using DCS at corresponding time points.

\subsection{Data Analysis}

Mean \pm standard deviation of cerebral hemodynamic parameters $\left(\mathrm{Hb}, \mathrm{HbO}_{2}, \mathrm{THC}, \mathrm{StO}_{2}\right.$, and $\left.\mathrm{rCBF}\right)$ from large sourcedetector separations $(1,1.5$, and $2 \mathrm{~cm})$ were reported for each individual animal. The total thickness of the scalp and skull layers of the piglet brain was $<4 \mathrm{~mm}$, and therefore, they should have a relatively small (compared to humans) influence on the accuracy of cerebral hemodynamic changes, especially relative changes, measured at large source-detector separations. ${ }^{23,25,32}$ Linear regression was used to demonstrate correlation and agreement between the FM and DCS measurements of rCBF. CBF measured with FMs in the upper cerebrum were normalized to the preinjury value from the same animal to obtain $\mathrm{rCBF}_{\mathrm{FM}}$ at various time points postinjury. $\mathrm{rCBF}$ measured using DCS $\left(\mathrm{rCBF}_{\mathrm{DCS}}\right)$ was averaged over 2 min at the corresponding FM time points. Measurements from the left and right hemispheres were averaged to improve the signal-to-noise ratio. The results from each experimental group were reported as mean \pm standard error. A one-way repeated measures analysis of variance (ANOVA) was employed to statistically interpret the group results. When significant differences were found, a Student t-test was used to determine the time point when significant changes occurred. Significance was adjusted for multiple comparisons using Bonferroni correction and $p \leqslant 0.01$.

\section{Results}

\subsection{Repeatability of Probe Placement}

From the six animals with double-baseline measurements, good agreement was observed between the first and second baseline measurements $(\mathrm{rCBF}=101 \pm 7 \%, \quad p=0.88$; rTHC $=108 \pm 12 \%, \quad p=0.54 ; \quad$ and $\mathrm{rStO}_{2}=107 \pm 7 \%$, $p=0.45$ ), indicating that removal and replacement of the probe had a relatively small influence on the measured optical cerebral hemodynamic values.

\subsection{Comparison of $\mathrm{rCBF}_{\mathrm{DCS}}$ to $\mathrm{rCBF}_{\mathrm{FM}}$}

Figure 2 compares rCBF obtained by DCS to rCBF by FMs in eight animals from the three groups. Regression analysis revealed a linear relationship between $\mathrm{rCBF}_{\mathrm{DCS}}$ and $\mathrm{rCBF}_{\mathrm{FM}}$, with a correlation coefficient of $R=0.89(p<0.00001)$. The

Table 2 Summary of physiological parameters in animal groups 1 and 2 (mean \pm standard error). VBG: venous blood gas; ABG: arterial blood gas. The asterisk in each row indicates significant difference from the corresponding pre-injury value $(p \leqslant 0.01)$.

\begin{tabular}{|c|c|c|c|c|c|c|c|}
\hline & Group & Preinjury & $<10 \min$ & $30 \mathrm{~min}$ & $1 \mathrm{~h}$ & $3 \mathrm{~h}$ & $6 \mathrm{~h}$ \\
\hline \multirow[t]{2}{*}{ HR (BPM) } & 1 & $169 \pm 12$ & $192 \pm 30$ & $178 \pm 27$ & $184 \pm 35$ & $175 \pm 25$ & $176 \pm 24$ \\
\hline & 2 & $179 \pm 23$ & $197 \pm 26$ & $192 \pm 24$ & $192 \pm 26$ & $198 \pm 26$ & $186 \pm 28$ \\
\hline \multirow[t]{2}{*}{ MAP (mmHg) } & 1 & $56 \pm 7$ & $59 \pm 16$ & $48 \pm 10$ & $50 \pm 9$ & $47 \pm 6 *$ & $44 \pm 6$ * \\
\hline & 2 & $58 \pm 12$ & $54 \pm 4$ & $54 \pm 10$ & $55 \pm 9$ & $52 \pm 7$ & $51 \pm 7$ \\
\hline \multirow[t]{2}{*}{$\mathrm{SaO}_{2}(\%)$} & 1 & $94 \pm 2$ & $92 \pm 12$ & $95 \pm 2$ & $96 \pm 1$ & $96 \pm 3$ & $96 \pm 4$ \\
\hline & 2 & $93 \pm 2$ & $94 \pm 4$ & $93 \pm 3$ & $94 \pm 3$ & $94 \pm 3$ & $96 \pm 2$ \\
\hline \multirow[t]{2}{*}{$\mathrm{EtCO}_{2}(\mathrm{mmHg})$} & 1 & $45 \pm 8$ & $49 \pm 12$ & $46 \pm 11$ & $43 \pm 9$ & $40 \pm 8$ & $40 \pm 10$ \\
\hline & 2 & $47 \pm 6$ & $43 \pm 6$ & $46 \pm 6$ & $43 \pm 6$ & $45 \pm 6$ & $47 \pm 7$ \\
\hline \multirow[t]{2}{*}{$\mathrm{pH}(\mathrm{VBG})$} & 1 & $7.30 \pm 0.05$ & $7.33 \pm 0.06$ & $7.32 \pm 0.08$ & $7.38 \pm 0.09$ & $7.39 \pm 0.04$ & $7.43 \pm 0.06$ \\
\hline & 2 & $7.37 \pm 0.12$ & - & $7.42 \pm 0.05$ & $7.38 \pm 0.02$ & 7.36 & $7.34 \pm 0.06$ \\
\hline \multirow[t]{2}{*}{$\mathrm{pH}(\mathrm{ABG})$} & 1 & $7.37 \pm 0.06$ & $7.38 \pm 0.08$ & $7.37 \pm 0.09$ & $7.41 \pm 0.09$ & $7.41 \pm 0.06$ & $7.40 \pm 0.08$ \\
\hline & 2 & $7.42 \pm 0.05$ & $7.45 \pm 0.06$ & $7.44 \pm 0.07$ & $7.47 \pm 0.05$ & $7.42 \pm 0.08$ & $7.35 \pm 0.09$ \\
\hline
\end{tabular}




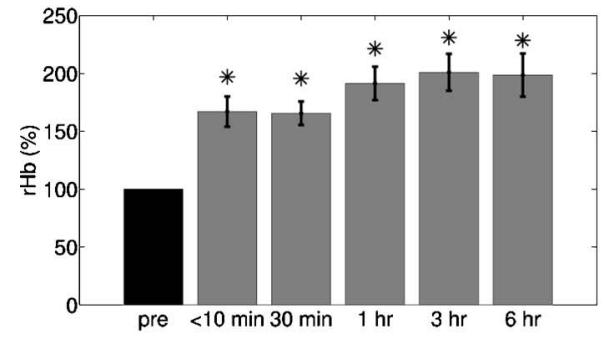

(A)

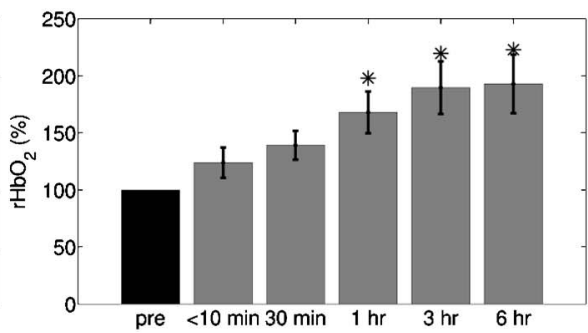

(B)

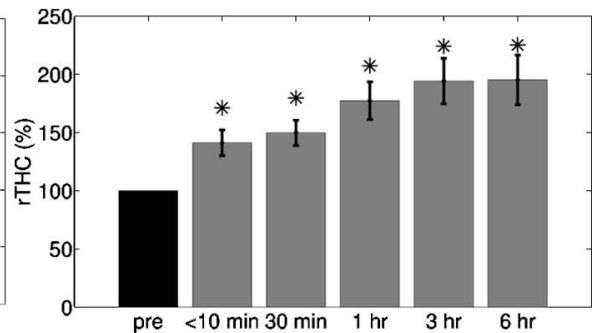

(C)

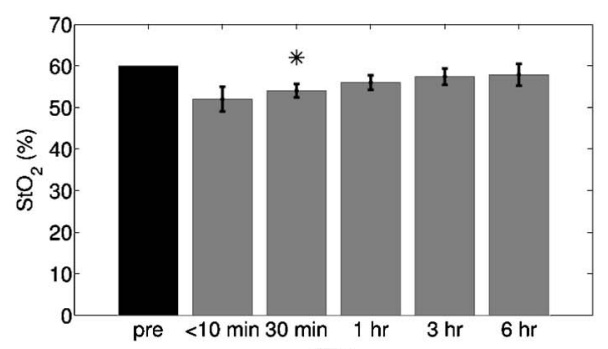

(D)

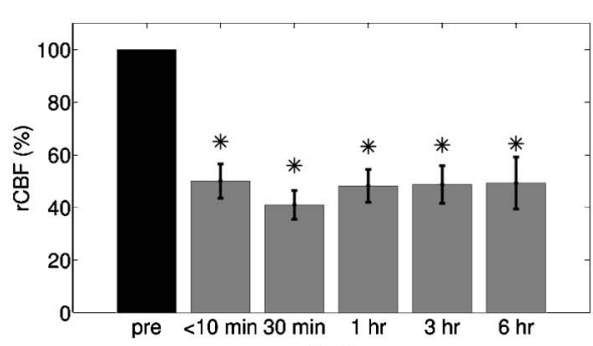

(E)

Fig. 3 Average injury effects on $\mathrm{Hb}, \mathrm{HbO}_{2}, \mathrm{THC}, \mathrm{StO}_{2}$, and $\mathrm{rCBF}$ for animals in group 1 ( $n=10$, error bars represent standard error). Traumatic brain injury produced significant increases in cerebral hemoglobin concentrations and decreases in oxygen saturation. Compared to preinjury levels, $\mathrm{rHb}, \mathrm{rHbO}_{2}$, and $\mathrm{rTHC}$ increased significantly within the first $10 \mathrm{~min}$ after injury and continued to increase over the next 6 h. StO ${ }_{2}$ dropped significantly by $30 \mathrm{~min}$ postinjury, but gradually returned to preinjury levels. rCBF decreased significantly within the first 10 min after injury and continued at that level over the $6 \mathrm{~h}$. The asterisk in each plot indicates a significant difference from the corresponding pre-injury value $(p \leqslant 0.01)$.

slope of the regression was calculated to be 1.03 (95\% confidence interval, CI: $0.74-1.32)$, which is not significantly different from identity $(p=0.80)$. The intercept was $25.2 \%$, with a $95 \%$ CI ranging from 12.4 to $38.0 \%$.

\subsection{Average Injury Effects}

Although each animal received individual care and had a distinct temporal hemodynamic response to the TBI, similar trends can be observed across animals within each of the groups. Changes in physiological parameters are summarized in Table 2. Compared to preinjury values, only MAP in group 1 was found significantly lower at $3 \mathrm{~h}(p=0.005)$ and $6 \mathrm{~h}$ $(p=0.002)$ and the 3 -h postinjury $\mathrm{pH}$ value in the venous blood gas (group 1) was significantly higher $(p=0.007)$.

Figure 3 demonstrates the average injury effects on cerebral hemodynamics measured optically from the 10 injured piglets in group 1. The traumatic brain injury was found to have a significant impact on cerebral hemoglobin concentrations (ANOVA, $p=0.001$ for $\mathrm{rHb}, p=0.01$ for $\mathrm{rHbO}_{2}$, and $p=0.005$ for $\mathrm{rTHC})$ and $\mathrm{rCBF}\left(p=3 \times 10^{-7}\right)$. Compared to preinjury levels, $\mathrm{rHb}, \mathrm{rHbO}_{2}$, and rTHC increased $67 \pm 13 \%$ $(p=0.0006), 24 \pm 13 \%(p=0.1)$, and $41 \pm 11 \%(p=0.005)$, respectively, immediately after injury and continued increasing over the next $6 \mathrm{~h}$ [see Fig. 3(a)-3(c)]. These changes are likely related to the accumulation of subdural and subarachnoid blood due to the rotational injury. $\mathrm{StO}_{2}$ dropped significantly immediately postinjury $(52 \pm 3 \%, p=0.02)$, maintained this reduction at $30 \mathrm{~min}$ postinjury $(54 \pm 2 \%$, $p=0.009$ ), but gradually normalized to preinjury levels [see Fig. 3(d)]. rCBF decreased significantly to $50 \pm 6 \%$ of preinjury level $(p=0.00003)$ immediately after injury and continued at that level over the $6 \mathrm{~h}$ [Fig. 3(e)]. By comparison, no significant changes in $\mathrm{rHb}$ (ANOVA, $p=0.32), \quad \mathrm{rHbO}_{2} \quad(p=0.68), \quad$ rTHC $\quad(p=0.18), \quad \mathrm{StO}_{2}$ $(p=0.92)$, or $\mathrm{rCBF}(p=0.87)$ were observed over the $6 \mathrm{~h}$ in the control group $(n=4)$.

\subsection{Robust Long-Term Monitoring}

All 14 injured piglets survived $6 \mathrm{~h}(n=10$ for group 1 and $n=4$ for group 3). Figure 4 shows the results of the $6 \mathrm{~h}$ monitoring period from a representative animal. Cerebral hemodynamic parameters measured with DRS and DCS, specifically $\mathrm{THC}, \mathrm{StO}_{2}$, and $\mathrm{rCBF}$, are shown in the top three panels. Vital physiological parameters, including MAP, $\mathrm{SaO}_{2}$, and $\mathrm{HR}$, are displayed in the bottom three panels. In this animal, THC increased to $84 \mu \mathrm{M}$ immediately after the injury, continued to gradually increase to $110 \mu \mathrm{M}$ during the first $2 \mathrm{~h}$, and then stayed at that level until $6 \mathrm{~h}$ postinjury. Blood oxygen saturation in the brain tissue $\left(\mathrm{StO}_{2}\right)$ and systemically $\left(\mathrm{SaO}_{2}\right)$ were relatively stable throughout the 6-h monitoring period. However, immediately after the injury, $\mathrm{rCBF}, \mathrm{MAP}$, and HR were elevated $(\mathrm{rCBF}=140 \%, \mathrm{MAP}=94 \mathrm{mmHg}, \mathrm{HR}=245 \mathrm{BPM})$, and then they decreased dramatically within the first $10 \mathrm{~min}$.

At $\sim 15$ min postinjury, phenylephrine infusion was begun via the femoral vein. Between marks M1 and M2, the phenylephrine dose was titrated until MAP was within $10 \mathrm{mmHg}$ of preinjury MAP. The resultant increases in MAP and rCBF can be observed in Fig. 4. The animal was maintained on the final phenylephrine dose $(1 \mu \mathrm{g} / \mathrm{kg} / \mathrm{min})$ until the end of the study. Between 4 and $5.5 \mathrm{~h}$, three boli of hypertonic (3\%) saline were injected into the animal (M3, M4, and M5). Good correlation between changes in MAP and $\mathrm{rCBF}$ were observed. Changes in HR were not found to correlate with $\mathrm{rCBF}$ changes over the $6 \mathrm{~h}$. Similar and consistent profiles were 

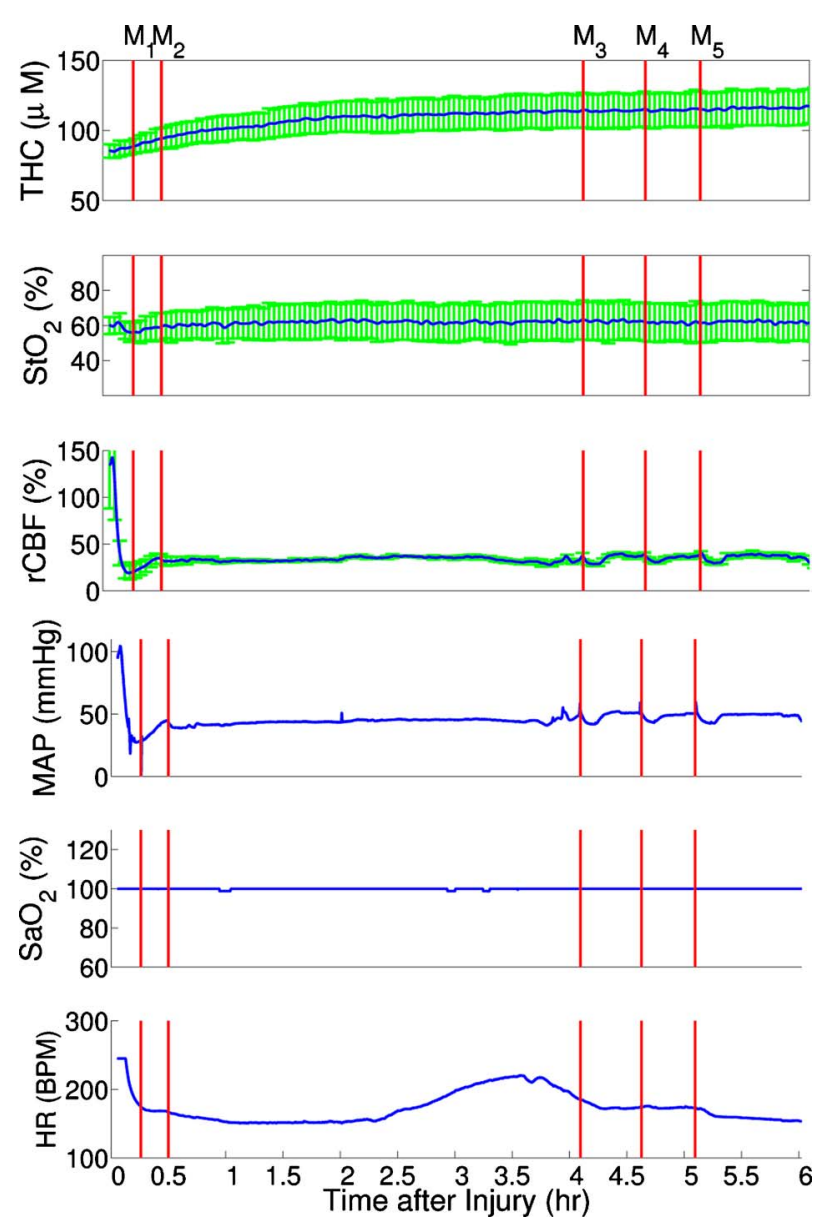

Fig. 4 Robust long-term monitoring from a representative animal. Cerebral hemodynamics ( $\mathrm{THC}, \mathrm{StO}_{2}$, and $\mathrm{rCBF}$ ) measured with DRS and DCS are plotted in the top three panels, while vital physiological parameters (MAP, $\mathrm{SaO}_{2}$, and $\mathrm{HR}$ ) are displayed in the bottom three panels. Good correlation between changes in MAP and changes in $\mathrm{rCBF}$ were observed. Solid vertical bars mark various physiological events: $M_{1}$, begin phenylephrine dose titration; $M_{2}$, begin continuous phenylephrine infusion at $1 \mu \mathrm{g} / \mathrm{kg} / \mathrm{min}$; and $M_{3}, M_{4}$, and $M_{5}$, administer boluses of hypertonic (3\%) saline. Error bars in the top three panels represent standard deviation of cerebral hemodynamic parameters from large source-detector separations $(1,1.5$, and $2 \mathrm{~cm})$.

observed from other animals in groups 1 and 3. Cerebral hemodynamics measured with diffuse optics were found to be robust and consistent with vital physiological recordings over the entire monitoring period.

\subsection{Sensitivity to Transient Physiological Events}

In addition to providing robust long-term monitoring capability, the diffuse optical techniques were sufficiently sensitive to capture the dynamics of transient physiological events, such as apnea, cardiac arrest, and hypertonic saline infusion. Examples in this section illustrate the temporal profiles of the measured cerebral hemodynamic changes during these events.

\subsubsection{Apnea}

Six episodes of spontaneous apnea from five animals in group 1 , two episodes from one animal in group 2 , and two episodes from two animals in group 3 were observed and recorded.
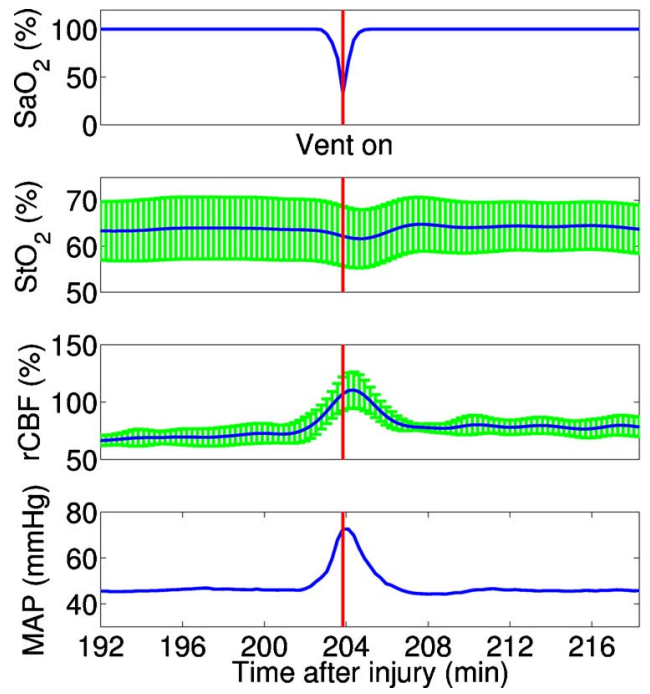

Fig. 5 Cerebral hemodynamic changes during an episode of apnea in a representative animal. Apnea caused a significant drop in $\mathrm{SaO}_{2}$. As a result, MAP increased significantly and raised rCBF to produce only a slight decrease in $\mathrm{StO}_{2}$. Following initiation of mechanical ventilation (solid vertical line), all physiological parameters returned to their preapnea states. Error bars in $\mathrm{StO}_{2}$ and $\mathrm{rCBF}$ represent standard deviation from large source-detector separations $(1,1.5$, and $2 \mathrm{~cm})$.

Figure 5 shows an example of an apnea event whose dynamics were captured optically. In this case, apnea caused a significant drop in systemic blood oxygen saturation (67\%). MAP rose by $26 \mathrm{mmHg}$, increasing blood flow to the brain by $36 \%$ relative to the preinjury value. $\mathrm{StO}_{2}$ decreased, but only by $\sim 2 \%$, most likely because the increased $\mathrm{rCBF}$ provided a sufficient increase in $\mathrm{O}_{2}$ delivery. Upon mechanical ventilation of the animal (the vertical marks in Fig. 5), all physiological parameters were successfully returned to their preapnea states. Because the duration of and response to apnea are different from animal to animal, the magnitudes of the changes in cerebral hemodynamics varied. However, the same trends (decreased $\mathrm{StO}_{2}$, increased MAP, and $\mathrm{rCBF}$ ) were observed consistently in all apnea events and were abolished by mechanical ventilation.

\subsubsection{Apnea followed by cardiac arrest}

Two apnea events were followed by cardiac arrest in one piglet in group 3, and cerebral hemodynamic changes during these episodes were recorded optically. As shown in Fig. 6(a), hemodynamics during the first period of apnea followed the same trends described above $\left(\mathrm{StO}_{2}\right.$ decreased from 57 to $48 \%$, MAP increased from 43 to $66 \mathrm{mmHg}$, and $\mathrm{rCBF}$ increased from 28 to $46 \%$ of preinjury levels). Cardiac arrest occurred about $3 \mathrm{~min}$ after the onset of apnea (the vertical marks in Fig. 6), producing a significant decrease in MAP to $13 \mathrm{mmHg}$. As a result, rCBF decreased dramatically to $13 \%$ and $\mathrm{StO}_{2}$ decreased further down to $37 \%$, indicating a significant decrease in oxygen delivery to the brain. About $4 \mathrm{~min}$ later, mechanical ventilation successfully resuscitated the animal from cardiac arrest. Initial increases in MAP were seen, which then gradually normalized to preapnea levels as $\mathrm{rCBF}$ and $\mathrm{StO}_{2}$ returned to preapnea values. Diffuse optical tech- 

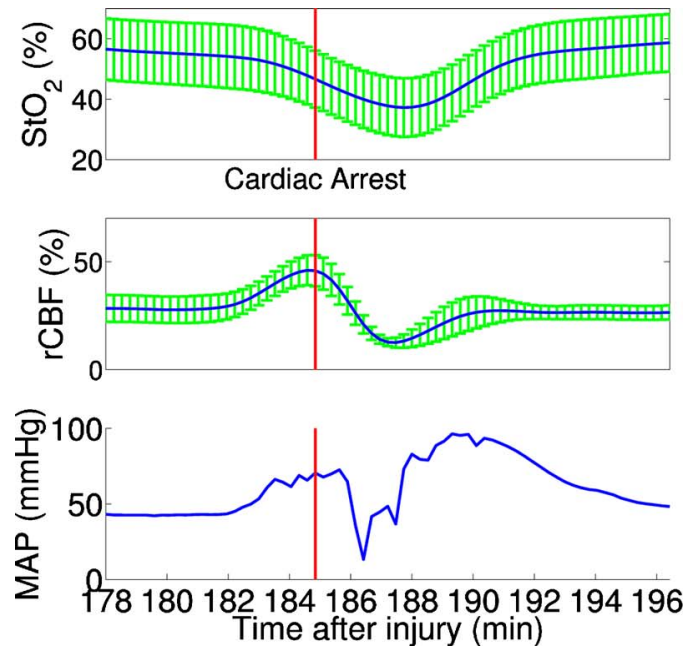

(A)
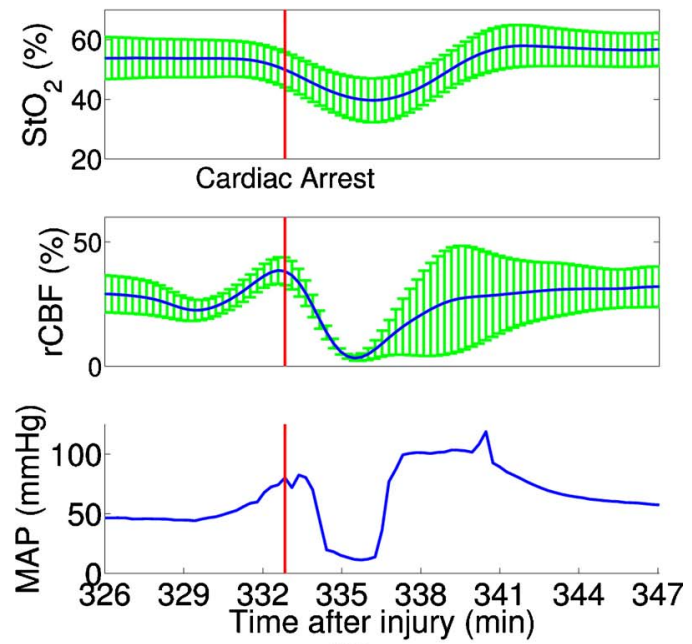

(B)

Fig. 6 Cerebral hemodynamic changes in a single animal during two episodes of apnea followed by cardiac arrest. (A) The onset of apnea produced the same $\mathrm{StO}_{2}, \mathrm{rCBF}$, and MAP trends observed in Fig. 5 . Cardiac arrest (solid vertical line) caused a significant decrease in MAP and $\mathrm{rCBF}$, resulting in a further significant decrease in $\mathrm{StO}_{2}$. After ventilatory resuscitation, $\mathrm{StO}_{2}, \mathrm{rCBF}$, and $\mathrm{MAP}$ gradually returned to preapnea levels. (B) The same "biphasic" dynamic change was observed during apnea in the same animal $2 \mathrm{~h}$ later. Error bars in $\mathrm{StO}_{2}$ and $\mathrm{rCBF}$ represent standard deviation from large source-detector separations $(1,1.5$, and $2 \mathrm{~cm})$.

niques captured similar dynamic changes following a second apnea event in the same animal two hours later [Fig. 6(b)].

\subsubsection{Hypertonic saline infusion}

Hypertonic (3\%) saline is widely employed in the clinical setting to increase cerebral blood flow by decreasing intracranial pressure and increasing systemic blood pressure. ${ }^{42}$ The effect is thought to work by extracting water from the tissue compartments, particularly swollen brain tissue, into the circulatory system. ${ }^{42}$ Four piglets in group $3(n=4)$ were infused with hypertonic saline over a 5 -min period starting $30 \mathrm{~min}$ postinjury. Temporal changes in $\mathrm{rCBF}$ and MAP from one representive example is displayed in Fig. 7. The infusion effectively elevated $\mathrm{rCBF}$ by $24 \%$ of preinjury levels and MAP
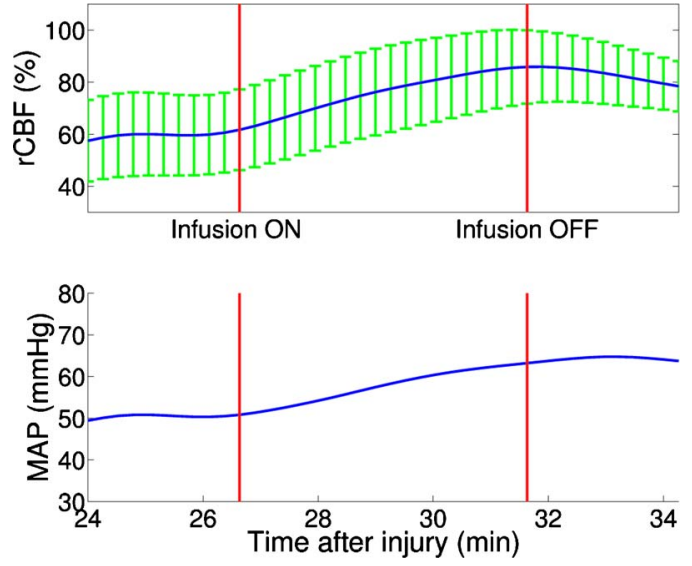

Fig. 7 Cerebral hemodynamic changes during hypertonic (3\%) saline infusion. The infusion effectively elevated $\mathrm{rCBF}$ and MAP. The solid vertical lines indicate the start and end of the infusion. Error bars in rCBF represent standard deviation from large source-detector separations $(1,1.5$, and $2 \mathrm{~cm})$.

by $12 \mathrm{mmHg}$. These rCBF and MAP changes were well correlated $(R=0.95)$ with each other. Similar trends were observed in the other animals receiving hypertonic saline.

\section{Discussion}

In the current study, rCBF measured with DCS was compared to $\mathrm{rCBF}$ with fluorescent microspheres. The comparison revealed excellent linear correlation $(R=0.89, p<0.00001)$, a close-to-identity slope of $1.03(p=0.80)$, and a $25.2 \%$ offset of DCS over FM measurements. However, due to the limited sample size (17 data points from eight animals), errors in the estimated slope and intercept are relatively large (95\% CI for slope: $0.74-1.32$; 95\% CI for intercept: 12.4-38.0\%).

The apparent offset between the two techniques may be accounted for by several factors. First, a biological zero signal, which has been extensively discussed in the laser Doppler literature, ${ }^{43}$ originates from the Brownian motion of the organelles inside the tissue and may contribute to a positive rCBF offset measured by DCS. From our postmortem DCS measurements in 18 animals (data not shown), we found that this effect contributes $\sim 8 \%$ to the offset of $25.2 \pm 6.4 \%$. In addition, the spatial heterogeneity of $\mathrm{CBF}$ and the incomplete match of the area of detection for the two techniques will certainly contribute to systematic differences between the two techniques, though this effect is difficult to estimate in the current setup; in a similar vein, the semi-infinite model employed for DCS data analysis can be improved. More importantly, the FM method is sensitive to small random fluctuations in the animal's physiological state, because the flow measurements are critically dependent on the precise timing of microsphere injection, reference blood withdrawal, etc. By comparison, the DCS method smoothes over these fluctuations by averaging continuous measurements over the corresponding time period. This difference may play a role in the apparent discrepancies between the two techniques, especially when the sample size is small, where random errors may be viewed as systematic errors. It was somewhat surprising to us, for example, that FM measurements in three control animals recorded an $20 \%$ reduction in $\mathrm{rCBF}$; these animals alone con- 
tribute substantially to the offset. In future studies, more animals will be employed to improve the quantification accuracy and procedures to account for tissue heterogeneity will be implemented at the outset.

Our most important finding, that DCS measurements respond linearly to $\mathrm{rCBF}$ changes, is consistent with previous observations comparing DCS to other relative blood flow measurement modalities, such as laser Doppler, ${ }^{7,36}$ colorweighted power Doppler ultrasound, ${ }^{33}$ Xenon $\mathrm{CT},{ }^{37}$ and ASL-MRI. ${ }^{38,39}$ The highly significant correlation between DCS and FMs thus provides further support for the use of DCS as a noninvasive tool for measuring relative changes in CBF.

The cerebral hemodynamic changes we observed following traumatic brain injury (see Fig. 3) are also consistent with observations by other researchers. ${ }^{44,45}$ The persistent $50 \%$ reduction in $\mathrm{CBF}$ is consistent with the findings from other TBI animal models, ${ }^{44,46}$ as well as human TBI patients. ${ }^{47}$ Bouma et al. reported $\mathrm{CBF}$ values of $<25 \mathrm{~mL} / \mathrm{min} / 100 \mathrm{~g}$ in adult patients with severe TBI within the first few hours of hospital admission, while normal $\mathrm{CBF}$ in adult humans is 45-50 mL/min/ $100 \mathrm{~g}^{48}$ A $40-50 \% \mathrm{CBF}$ reduction persisting for at least $4 \mathrm{~h}$ has been reported in rats following fluid percussion injury (FPI). ${ }^{46}$ FPI in neonatal piglets has been shown by Ref. 44 to cause an immediate and sustained decrease in cerebral blood flow $(\sim 30 \%)$ and a prolonged decrease in mean arterial pressure up to $3 \mathrm{~h}$ following injury, but relatively mild axonal injury and subarachnoid bleeding. ${ }^{44}$ In the current study, MAP decreased significantly only after $3 \mathrm{~h}$ and was not sufficient to explain the observed immediate and persistant blood flow reductions, which therefore could be attributed to damaged or dysfunctional regulation of the cerebral vessels.

All of our injured animals had subdural and subarachnoid hematoma on necropsy. This finding was consistent with the continuous increase in hemoglobin concentrations we observed in these animals over the course of the 6-h postinjury period. We should note that the influence of extra-axial blood on the accuracy of the DCS measurements was minimized, by continuously monitoring and incorporating any timedependent changes in the absorption coefficient of the piglet brain into the DCS data analysis.

While our acquisition rate of 4 frames/min was sufficient to capture cerebral hemodynamic changes during physiological perturbations, such as apnea, cardiac arrest, and hypertonic saline infusion, this rate could potentially be improved for even greater dynamic accuracy without sacrificing the signal-to-noise ratio by monitoring a smaller number of source-detector pairs or employing more parallel detection. A faster detection system would lend itself to the development of algorithms for online detection of physiological events that could provide cerebral blood flow or cerebral oxygenationspecific triggering alarms in the intensive care unit. For example, in the case of apnea or cardiac arrest, as illustrated in Figs. 5 and 6, alarms could be triggered based on integrating the $\mathrm{SaO}_{2}, \mathrm{StO}_{2}, \mathrm{rCBF}$, and MAP information into a cerebral metabolic insufficiency alarm that would indicate the need for immediate intervention.

Other potential future innovations include implementation of tomographic blood flow image reconstruction, an approach that has been demonstrated in rats by measuring DCS signals at multiple source-detector pairs ${ }^{7,9}$ and combined uses of blood flow and oxygenation to generate regional maps of the cerebral metabolic rate of oxygen, ${ }^{49-51}$ another important indicator of the well-being of the brain. With improvement of the DCS signal-to-noise ratio, 9,52 these applications will be extended to larger animals and to humans, where probes with larger source-detector separation are required to permit detection through thicker scalp and skull.

Finally, in this study, we demonstrated that diffuse optical techniques (DRS and DCS) have the robustness and sensitivity needed for patient monitoring at the bedside. During the 6-h monitoring period in the current study, physiological events were clearly marked and coregistered with vital physiological parameters and optical recordings. Cerebral hemodynamics measured optically were found to be consistent and complementary to vital recordings, physiological events, and pathological findings. Although quantification of absolute cerebral hemodynamic parameters is desirable, the relative measurements presented in this study are valuable for many clinical applications. For example, we have made progress recently in pilot studies using these techniques for bedside monitoring and cerebral autoregulation assessment in intensive care unit for infants and adult humans. ${ }^{37,39,53,54}$ In one of the studies, ${ }^{54}$ relative hemodynamic changes in respond to head-of-bed perturbation were found to differ significantly between healthy subjects and stroke patients.

\section{Conclusion}

In summary, using a newborn piglet traumatic brain injury model we have demonstrated that diffuse optical techniques (DRS and DCS) are capable of probing cerebral hemodynamics noninvasively through intact scalp and skull. We validated rCBF measured using the DCS technique against the FM method, wherein a strong linear correnpondance was observed. TBI was found to significantly reduce cerebral blood flow and raise intracranial hemoglobin concentrations. The diffuse optical techniques are robust for long-term monitoring at bedside and sensitive to spontaneous physiological events, such as apnea and cardiac arrest, as well as physiological perturbations, such as hypertonic saline infusion. These techniques hold great potential for application in pediatric and adult human patients in the neurointensive care unit.

\section{Acknowledgment}

This work was supported by the NIH grants No. RO1-HL077699 (A.G.Y.), No. RO1-NS-39679 (S.S.M.), and No. ED26979 (T.D.) and Thrasher research Fund New Researcher Award NR-0016 (T.D.). The authors thank Regine Choe, Erin Buckley, and Janos Luckl for their assistance in this study, and Joel H. Greenberg for useful discussions.

\section{References}

1. M. D. Fisher, "Pediatric traumatic brain injury," Crit. Care Nurs. Q. 20, 36-51 (1997).

2. R. Raghupathi and S. S. Margulies, "Traumatic axonal injury after closed head injury in the neonatal pig," J. Neurotrauma 19(7), 843853 (2002).

3. J. W. T. Dickerson and J. Dobbing, "Prenatal and postnatal growth and development of the central nervous system of the pig," Proc. $R$. Soc. London 166, 384-395 (1967). 
4. S. Friess, R. Ichord, K. Owens, J. Ralston, R. Rizol, K. Overall, C Smith, M. Helfaer, and S. Margulies, "Neurobehavioral functional deficits following closed head injury in the neonatal pig," Exp. Neurol. 204(1), 234-243 (2007).

5. A. Villringer and B. Chance, "Non-invasive optical spectroscopy and imaging of human brain function," Trends Neurosci. 20, 435-442 (1997).

6. A. P. Gibson, J. C. Hebden, and S. R. Arridge, "Recent advances in diffuse optical imaging," Phys. Med. Biol. 50(4), R1-R43 (2005).

7. J. P. Culver, T. Durduran, T. Furuya, C. Cheung, J. H. Greenberg, and A. G. Yodh, "Diffuse optical tomography of cerebral blood flow, oxygenation, and metabolism in rat during focal ischemia," J. Cereb. Blood Flow Metab. 23, 911-924 (2003).

8. T. Durduran, G. Q. Yu, M. G. Burnett, J. A. Detre, J. H. Greenberg, J. Wang, C. Zhou, and A. G. Yodh, "Diffuse optical measurement of blood flow, blood oxygenation, and metabolism in a human brain during sensorimotor cortex activation," Opt. Lett. 29, 1766-1768 (2004).

9. C. Zhou, G. Q. Yu, D. Furuya, J. H. Greenberg, A. G. Yodh, and T. Durduran, "Diffuse optical correlation tomography of cerebral blood flow during cortical spreading depression in rat brain," Opt. Express 14, 1125-1144 (2006).

10. J. Li, G. Dietsche, D. Iftime, S. E. Skipetrov, G. Maret, T. Elbert, B. Rockstroh, and T. Gisler, "Noninvasive detection of functional brain activity with near-infrared diffusing-wave spectroscopy," J. Biomed. Opt. 10(4), 044002 (2005).

11. F. Jaillon, J. Li, G. Dietsche, T. Elbert, and T. Gisler, "Activity of the human visual cortex measured non-invasively by diffusing-wave spectroscopy," Opt. Express 15, 6643-6650 (2007).

12. D. W. Brown, J. Hadway, and T. Y. Lee, "Near-infrared spectroscopy measurement of oxygen extraction fraction and cerebral metabolic rate of oxygen in newborn piglets," Pediatr. Res. 54(6), 861-867 (2003).

13. A. M. Rudolph and M. A. Heymann, "The circulation of the fetus in utero. methods for studying distribution of blood flow, cardiac output and organ blood flow," Circ. Res. 21(2), 163-184 (1967).

14. G. De Visscher, M. Haseldonckx, W. Flameng, M. Borgers, R. S. Reneman, and K. van Rossem, "Development of a novel fluorescent microsphere technique to combine serial cerebral blood flow measurements with histology in the rat," J. Neurosci. Methods 122(2), 149-156 (2003).

15. K. M. Powers, C. Schimmel, R. W. Glenny, and C. M. Bernards, "Cerebral blood flow determinations using fluorescent microspheres: variations on the sedimentation method validated," J. Neurosci. Methods 87(2), 159-165 (1999).

16. A. Polito, Z. Ricci, L. Di Chiara, C. Giorni, C. Iacoella, S. P. Sanders, and S. Picardo, "Cerebral blood flow during cardiopulmonary bypass in pediatric cardiac surgery: the role of transcranial Doppler-a systematic review of the literature," Cardiovasc. Ultrasound 4, 47-47 (2006).

17. R. Bonner and R. Nossal, "Model for laser Doppler measurements of blood flow in tissue," Appl. Opt. 20, 2097-2107 (1981).

18. F. F. Jöbsis, "Noninvasive, infrared monitoring of cerebral and myocardial oxygen sufficiency and circulatory parameters," Science 198(4323), 1264-1267 (1977).

19. M. Cope and D. T. Delpy, "System for long-term measurement of cerebral blood and tissue oxygenation on newborn infants by near infra-red transillumination," Med. Biol. Eng. Comput. 26(3), 289-294 (1988).

20. A. D. Edwards, J. S. Wyatt, C. Richardson, D. T. Delpy, M. Cope, and E. O. Reynolds, "Cotside measurement of cerebral blood flow in ill newborn infants by near infrared spectroscopy," Lancet 2(8614), 770-771 (1988)

21. K. Isobe, T. Kusaka, Y. Fujikawa, M. Kondo, K. Kawada, S. Yasuda, S. Itoh, K. Hirao, and S. Onishi, "Changes in cerebral hemoglobin concentration and oxygen saturation immediately after birth in the human neonate using full-spectrum near infrared spectroscopy," $J$. Biomed. Opt. 5(3), 283-286 (2000).

22. F. Nomura, H. Naruse, A. duPlessis, T. Hiramatsu, J. Forbess, D Holtzman, J. J. Volpe, R. Jonas, and M. Tsuji, "Cerebral oxygenation measured by near infrared spectroscopy during cardiopulmonary bypass and deep hypothermic circulatory arrest in piglets," Pediatr. Res. 40(6), 790-796 (1996)

23. S. Fantini, D. Hueber, M. A. Franceschini, E. Gratton, W. Rosenfeld, P. G. Stubblefield, D. Maulik, and M. R. Stankovic, "Non-invasive optical monitoring of the newborn piglet brain using continuouswave and frequency-domain spectroscopy," Phys. Med. Biol. 44(6), 1543-1563 (1999).

24. G. Zhang, A. Katz, R. R. Alfano, A. D. Kofinas, D. A. Kofinas, P. G. Stubblefield, W. Rosen-feld, D. Beyer, D. Maulik, and M. R. Stankovic, "Brain perfusion monitoring with frequency-domain and continuous-wave near-infrared spectroscopy: a cross-correlation study in newborn piglets," Phys. Med. Biol. 45(11), 3143-3158 (2000).

25. D. M. Hueber, M. A. Franceschini, H. Y. Ma, Q. Zhang, J. R. Ballesteros, S. Fantini, D. Wallace, V. Ntziachristos, and B. Chance, "Non-invasive and quantitative near-infrared hemoglobin spectrometry in the piglet brain during hypoxic stress, using a frequencydomain multidistance instrument," Phys. Med. Biol. 46(1), 41-62 (2001).

26. D. A. Boas and A. G. Yodh, "Spatially varying dynamical properties of turbid media probed with diffusing temporal light correlation," $J$. Opt. Soc. Am. A 14(1), 192-215 (1997).

27. D. A. Boas, L. E. Campbell, and A. G. Yodh, "Scattering and imaging with diffusing temporal field correlations," Phys. Rev. Lett. 75(9), 1855-1858 (1995).

28. G. Maret and P. Wolf, "Multiple light scattering from disordered media. The effect of Brownian motion of scatterers," Z. Phys. B: Condens. Matter 65, 409-413 (1987).

29. D. Pine, D. Weitz, P. Chaikin, and E. Herbolzheimer, "Diffusingwave spectroscopy," Phys. Rev. Lett. 60, 1134-1137 (1988).

30. J. F. Nunn, Applied Respiratory Physiology, Butterworth-Heinemann, London (1993).

31. D. T. Delpy, M. Cope, P. van der Zee, S. Arridge, S. Wray, and J. Wyatt, "Estimation of optical pathlength through tissue from direct time of flight measurement," Phys. Med. Biol. 33, 1433-1442 (1988).

32. S. Ijichi, T. Kusaka, K. Isobe, F. Islam, K. Okubo, H. Okada, M Namba, K. Kawada, T. Imai, and S. Itoh, "Quantification of cerebral hemoglobin as a function of oxygenation using near-infrared timeresolved spectroscopy in a piglet model of hypoxia," J. Biomed. Opt. 10(2), 024026 (2005).

33. G. Q. Yu, T. Durduran, C. Zhou, H. W. Wang, M. E. Putt, H. M. Saunders, C. M. Sehgal, E. Glatstein, A. G. Yodh, and T. M. Busch, "Noninvasive monitoring of murine tumor blood flow during and after photodynamic therapy provides early assessment of therapeutic efficacy," Clin. Cancer Res. 11(9), 3543-3552 (2005).

34. T. Durduran, R. Choe, G. Yu, C. Zhou, J. C. Tchou, B. J. Czerniecki, and A. G. Yodh, "Diffuse optical measurement of blood flow in breast tumors," Opt. Lett. 30, 2915-2917 (2005).

35. C. Zhou, R. Choe, N. Shah, T. Durduran, G. Yu, A. Durkin, D. Hsiang, R. Mehta, J. Butler, A. Cerussi, B. J. Tromberg, and A. G. Yodh, "Diffuse optical monitoring of blood flow and oxygenation in human breast cancer during early stages of neoadjuvant chemotherapy," J. Biomed. Opt. 12(5), 051903 (2007).

36. C. Cheung, J. P. Culver, K. Takahashi, J. H. Greenberg, and A. G. Yodh, "In vivo cerebrovascular measurement combining diffuse nearinfrared absorption and correlation spectroscopies," Phys. Med. Biol. 46(8), 2053-2065 (2001).

37. T. Durduran, M. N. Kim, E. M. Buckley, B. L. Edlow, H. Moss, C. Zhou, G. Yu, R. Choe, S. K. Frangos, E. Wilensky-Mahoney, A. Kofke, J. M. Levine, R. L. Wolf, J. Woo, S. E. Kasner, B. L. Cucchiara, M. E. Putt, A. G. Yodh, J. H. Greenberg, and J. A. Detre, "Bedside monitoring of cerebral hemodynamics for stroke and neurocritical care using novel diffuse optical probes," presented at Annual Mtg of American Neurological Association, Abstract 298 (2008).

38. G. Q. Yu, T. Floyd, T. Durduran, C. Zhou, J. J. Wang, J. A. Detre, and A. G. Yodh, "Validation of diffuse correlation spectroscopy for muscle blood flow with concurrent arterial spin labeled perfusion MRI," Opt. Express 15(3), 1064-1075 (2007).

39. T. Durduran, C. Zhou, M. N. Kim, E. M. Buckley, G. Yu, R. Choe, S. M. Durning, S. Mason, L. M. Montenegro, S. C. Nicholson, R. A. Zimmerman, J. J. Wang, J. A. Detre, A. G. Yodh, and D. J. Licht, "Validation of diffuse correlation spectroscopy for non-invasive, continuous monitoring of $\mathrm{CBF}$ in neonates with congenital heart defects," presented at Annual Mtg of American Neurological Association, Abstract 299 (2008).

40. T. Durduran, "Noninvasive measurements of tissue hemodynamics with hybrid diffuse optical methods," Ph.D. Thesis, University of Pennsylvania (2004).

41. G. Q. Yu, T. Durduran, G. Lech, C. Zhou, B. Chance, R. E. Mohler, 
and A. G. Yodh, "Time-dependent blood flow and oxygenation in human skeletal muscles measured with noninvasive near-infrared diffuse optical spectroscopies," J. Biomed. Opt. 10, 024027 (2005).

42. J. A. Doyle, D. P. Davis, and D. B. Hoyt, "The use of hypertonic saline in the treatment of traumatic brain injury," Sitzungsber. K. Preuss. Akad. Wiss. 50(2), 367-383 (2001).

43. D. P. Kernick, J. E. Tooke, and A. C. Shore, "The biological zero signal in laser Doppler fluximetry-origins and practical implications," Pfluegers Arch. 437(4), 624-631 (1999).

44. W. M. Armstead and C. D. Kurth, "Different cerebral homodynamic responses following fluid percussion brain injury in the newborn and juvenile pig," J. Neurotrauma 11(5), 487-497 (1994).

45. S. R. Durham, R. Raghupathi, M. A. Helfaer, S. Marwaha, and A. C. Duhaime, "Age-related differences in acute physiologic response to focal traumatic brain injury in piglets," Pediatr. Neurosurg. 33(2), 76-82 (2000).

46. X. Q. Yuan, D. S. Prough, T. L. Smith, and D. S. Dewitt, "The effects of traumatic brain injury on regional cerebral blood flow in rats," $J$. Neurotrauma 5(4), 289-301 (1988).

47. G. J. Bouma, J. P. Muizelaar, S. C. Choi, P. G. Newlon, and H. F. Young, "Cerebral circulation and metabolism after severe traumatic brain injury: the elusive role of ischemia," J. Neurosurg. 75(5), 685693 (1991).

48. J. Overgaard and W. A. Tweed, "Cerebral circulation after head injury. 1. cerebral blood flow and its regulation after closed head injury with emphasis on clinical correlations," J. Neurosurg. 41(5), 531-541 (1974).
49. F. Hyder, R. G. Shulman, and D. L. Rothman, "A model for the regulation of cerebral oxygen delivery," J. Appl. Physiol. 85(2), 554564 (1998)

50. R. D. Hoge, J. Atkinson, B. Gill, G. R. Crelier, S. Marrett, and G. B. Pike, "Investigation of BOLD signal dependence on cerebral blood flow and oxygen consumption: the deoxyhemoglobin dilution model," Magn. Reson. Med. 42(5), 849-863 (1999).

51. J. B. Mandeville, J. J. Marota, C. Ayata, M. A. Moskowitz, R. M. Weisskoff, and B. R. Rosen, "MRI measurement of the temporal evolution of relative $\mathrm{CMRO}(2)$ during rat forepaw stimulation," Magn. Reson. Med. 42(5), 944-951 (1999).

52. G. Dietsche, M. Ninck, C. Ortolf, J. Li, F. Jaillon, and T. Gisler, "Fiber-based multispeckle detection for time-resolved diffusing-wave spectroscopy: characterization and application to blood flow detection in deep tissue," Appl. Opt. 46(35), 8506-8514 (2007).

53. T. Durduran, C. Zhou, G. Yu, B. Edlow, R. Choe, Q. Shah, S. E. Kasner, B. L. Cucchiara, A. G. Yodh, J. H. Greenberg, and J. A. Detre, "Bed-side monitoring of cerebral blood flow (CBF) in acute stroke patients during changes in head of bed position," presented at the Int. Stroke Conf., Vol. P37, American Heart Association, San Francisco (2007).

54. T. Durduran, C. Zhou, B. L. Edlow, G. Q. Yu, R. Choe, M. N. Kim, B. L. Cucchiara, M. Putt, Q. Shah, S. E. Kasner, J. H. Greenberg, A. G. Yodh, and J. A. Detre, "Transcranial optical monitoring of cerebrovascular hemodynamics in acute stroke patients," Opt. Express 17, 3884-3902 (2009). 